\title{
Very Unusual Case Report: Type RIII of Lipton’s Classification
}

\section{Zülküf Karahan*, Bernas Altıntaş, Murat Ugurlu and İlyas Kaya}

Department of Cardiology, Gazi Yasargil Education and Research Hospital, Diyarbakır, Turkey

\author{
Abstract \\ Single coronary artery is a very rare congenital anomaly in the general population. We presented a 51 year-old \\ male with typical chest pain, and coronary angiogram showed a single trunk from the right coronary sinus.
}

Keywords: Coronary anomaly; Single trunk; Lipton's classification

\section{Introduction}

A single coronary artery (SCA) is very rare anomaly with an incidence of $0.01 \%$ to $0,004 \%$ in the general population and arises from the aortic trunk from a single coronary ostium [1,2]. Lipton et al. [3] classifield the SCA anomalies according to the site of origin from the left and right coronary arteries. We present a rare case report and, the anomalous SCA was classified as R III subtype according to Lipton's classification.

\section{Case Report}

A 51 year-old male patient admitted to us with typical exertional angina. The patient had dyslipidemia and, his risk factor was current smoking. Physical examination was normal. His blood pressure was 120/70 mmHg. Electrocardiography showed normal sinus rhythm of 72 beats per minute. Transthoracic echocardiography showed a large right coronary artery arising from the right sinus of valsalva in the parasternal short axis (Figure 1). Coronary angiography was performed and, left coronary system could not be imaged with left Judkins chateter. A single trunk of coronary artery originated from right sinus valsalva, giving rise to the right coronary artery (RCA), left circumflex coronary artery (CX) and left anterior descending coronary artery (LAD), was shown by right Judkins chateter. The RCA has a normal course, and the LAD has an anterior to the large vessels course, and the CX has a retroaortic course (Figure 2).

\section{Discussion}

The patients with single coronary artery are generally asymptomatic and, this anomaly found accidentally undergoing coronary arteriography. The clinical significance mainly depends on the course of the SCA in relation to the great arteries with a course between the pulmonary artery and the aorta being at risk to arrhythmias, ischemia and sudden death especially during exercise [4].

There are several classifications of single coronary arteries. However, the most practical is the classification by Lipton et al. according to the origin; from left ( $\mathrm{L}$ type) or right ( $\mathrm{R}$ type) sinus of Valsalva [3]. We reported patients with an example of R-III type, of which the single coronary artery arising from the right sinus, with the left anterior descending and circumflex arteries from separate coronary artery trunks instead of a single trunk immediately at the exit. The incidence of anomalous origins of left coronary artery from the right sinus valsalva is $0.017 \%$ and the incidence of R-III type is $0.004 \%$ [3].

\section{Conclusion}

We presented a single coronary artery case with the R-III type which is a very rare type comparing with other types of single coronary artery originating from right sinus valsalva.

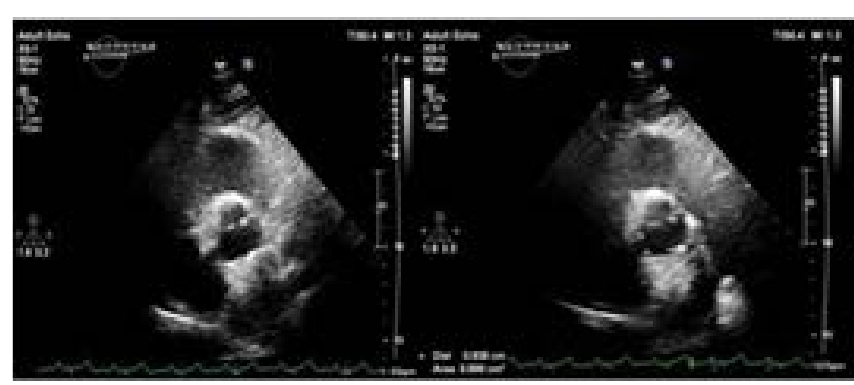

Figure 1: Transthoracic echocardiography showed a large right coronary artery arising from the right sinus of valsalva in the parasternal short axis.

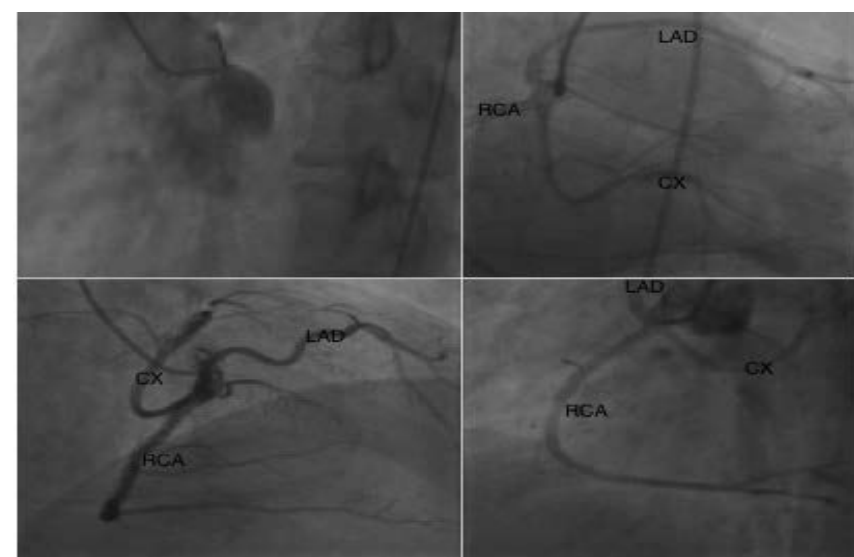

Figure 2: The RCA has a normal course, and the LAD has an anterior to the large vessels course, and the CX has a retroaortic course.

\section{References}

1. Yamanaka O, Hobbs RE (1990) Coronary artery anomalies in patients undergoing coronary arteriography. Cathet Cardiovasc Diagn 21: 28-40.

*Corresponding author: Zülküf Karahan, Department of Cardiology, Gazi Yasargil Education and Research Hospital, Diyarbakır, Turkey, Tel: +905336358695; E-mail: zerkif@mynet.com

Received February 02, 2016; Accepted February 26, 2016; Published February 29, 2016

Citation: Karahan Z, Altıntaş B, Ugurlu M, Kaya I (2016) Very Unusual Case Report: Type RIII of Lipton's Classification. J Cardiovasc Dis Diagn 4: 235. doi:10.4172/2329-9517.1000235

Copyright: @ 2016 Karahan Z, et al. This is an open-access article distributed under the terms of the Creative Commons Attribution License, which permits unrestricted use, distribution, and reproduction in any medium, provided the original author and source are credited. 
Citation: Karahan Z, Altıntaş B, Ugurlu M, Kaya İ (2016) Very Unusual Case Report: Type RIII of Lipton's Classification. J Cardiovasc Dis Diagn 4: 235. doi:10.4172/2329-9517.1000235

Page 2 of 2

2. Desmet $W$, Vanhaecke J, Vrolix M, Van de Werf F, Piessens J, et al. (1992) Isolated single coronary artery: a review of 50,000 consecutive coronary angiographies. Eur Heart J 13: 1637-1640.

3. Lipton MJ, Barry WH, Obrez I, Silverman JF, Wexler L (1979) Isolated single coronary artery: diagnosis, angiographic classification, and clinical significance. Radiology 30: 39-47.

4. Shirani J, Roberts WC (1993) Solitary coronary ostium in the aorta in the absence of other major congenital cardiovascular anomalies. J Am Coll Cardio 21: 137-143. 